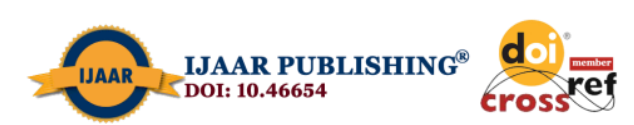

International Journal of Advanced Academic Research (Social and Management Sciences) | ISSN: 2488-9849

Journal DOI: 10.46654/ij.24889849

Vol. 6, Issue 12 (December, 2020)| www.ijaar.org

Article DOI: 10.46654/ij.24889849.s61219

\title{
TRANSPORTATION MODEL AND COST CONTROL IN NIGERIAN MANUFACTURING FIRMS
}

\author{
STANFAST SUOTONYE BARNABAS \\ Department of Management, \\ Faculty of Management Sciences, \\ Niger Delta University, Wilberforce Island, Amassoma. Bayelsa State, Nigeria. \\ barnabasy2k@yahoo.com \\ 08036716199 \\ MARIAN LAWRENCE APOH (Ph.D) \\ Department of Management, \\ Faculty of Management Sciences, \\ Niger Delta University, Wilberforce Island, Amassoma. Bayelsa State, Nigeria. \\ divinemercies7@yahoo.com \\ 09086762218
}

\begin{abstract}
The value of effective cost control in organizations, especially manufacturing companies, cannot be overestimated. Effective cost management creates significant business opportunities. This allows companies to pay off debt, thus reducing the amount of debt into cash. Cost control increases corporate profits and improved profits lead to the purchase of better, more efficient and renewable equipment. The product is delivered at a cost that does not add value in terms of quantity, quantity or quality, but you usually sell the product for a profit. These costs are borne by the manufacturer or buyer by increasing the cost of production or the price of the goods. Manufacturers and service providers are therefore constantly making efforts to reduce shipping costs and the use of transport modeling methods is a strategy proposed by experts. The purpose of this measurement study was to examine the relationship between transportation model and cost control in manufacturing organizations. The number of sample frame includes ten manufacturing companies in Rivers State, Nigeria with 103 participants. The Spearman Rank Order Correlation Coefficient discloses that the use of transportation model has a positive impact on the cost of goods shipped, the quantity of goods shipped and the reliability of delivery.
\end{abstract}

Keywords: Transportation model, cost control, shipping price, quantity of goods shipped and delivered, reliability. 


\subsection{Introduction}

Businesses aim to produce products at low cost to achieve the goal of maximizing profits. Business executives attempt to control costs through a financial management tool (Cyanbola \& Compromise, 2013); they use a cost control method to improve its efficiency. Cost management means using the most economical method of completing each task (Wizzevinsky, 1986) in a workplace with very little or no waste. This area includes rules, procedures, and procedures known as standard operating procedures (SOP). These standards clearly define the fraction of the minimum cost required to complete a given product cycle and require all operators to follow these cost control guidelines in their workplace. Cost control can be defined as an acceptable level of determining the comparable waste potential of actual results and, if any, taking appropriate measures to duplicate and / or reduce that waste if necessary (Cooper \& Slogmulder, 1999).

Cost control is defined as the process by which business managers control part of the cost of performing a specific function in an organization. It is not limited to production, but all organizational performance. This strategy allows companies to achieve sales objectives, improve profits and remain highly competitive. In the absence of cost control, profits fall sharply despite a growing sales volume.

The value of effective cost control in organizations, especially manufacturing companies, cannot be overestimated. Effective cost control creates significant business opportunities. This allows companies to pay off debt, thus reducing the amount of debt into cash. If the equity ratio resulting from the firm's debt, its financial capacity and credit rating, cost control can increase a company's profits and turn a profit on buying better, more efficient and improved equipment (Jacobs, Chase, \& Lumus, 2014). These devices require minimal maintenance and repair because they are new, efficient and updated. Effective cost control provides additional funding for aggressive marketing campaigns that bring marketing and advertising activities, acquisition of key equipment and competitive advantage. All of these guarantees increase productivity from employees and ultimately increase profits (Ferreira \& Merchant, 1992).

An effective cost control system provides employees with a framework for managing their work, with little or no waste. Through the process of cost control, increased profitability and corporate governance motivates employees through wage increases. It has a tendency to increase work ethics and employee benefits. A company with a competitive pay structure has the potential to attract better employees with the necessary skills and competencies.

Anthony and Govindarajan (2007) found that in developing countries such as Nigeria, in order for producers to remain competent and competitive in the business world, they must continue to use cost control and cost-cutting strategies. In addition to cost control, product availability to consumers is critical to the survival of any manufacturing company because the best quality product and price must reach the end consumer before it can be claimed as a financial return on corporate life (Cashine, Polymene, \& Handy, 1994).

The product is delivered at a cost that does not add value in terms of quantity, quantity or quality, but you usually sell the product for a profit. These costs are borne by the manufacturer or buyer by increasing the cost of production or the price of the goods. Inflation may be undesirable when competitors sell at a lower price, therefore, the manufacturer must acquire and accept delivery costs as low as possible in order to maintain dominance over 
competitors. The improvement in the cost of distribution from an effective cost management system can be translated into the net income benefit over time.

The cost of travel and / or delivery depends on the mode of transport chosen and the specific mode of transport chosen depends on the needs of the organization (Yim, Wang, Chen, Wang, Wang, \& Lam, 2011). In Nigeria, roads are a means of transportation as they account for $90 \%$ of internal passenger and freight traffic (Mishra, 2017). Manufacturing companies try to reduce their shipping costs, increase profits against competitors, or lower the price of their goods and services. Anthony and Govindarajan (2007) argue that a company with a cost-effective approach has great potential to achieve its profit objectives.

Rising commodity prices have forced many producers to produce lower-quality materials, thus reducing production costs and increasing profits. However, as the number of competitors grows, many manufacturers have resorted to the option of using quality packaging products, as this is the most accurate and most effective way to increase profits. Cost control / reduction and profitability are paramount for many companies and in order to achieve this goal, business managers need to understand the factors that increase profitability and reduce costs (Lucy, 2002).

The deteriorating economic situation of developing countries such as Nigeria is increasing competition and the survival race is intensifying, thus increasing the need for cost control and cost reduction. Therefore, the need to learn various tools and methods of cost control. Manufacturers need to understand costs, the need for cost control, the type of price to charge depending on their environment and the different areas where costs can be controlled.

The financial position of an entity is determined by the efficiency of cost control and profit growth. As business performance is measured by their level of profitability, many businesses, especially productive concerns, seek to increase their sales value and the need for higher sales leads to increased demand for productivity, which in turn increases costs. Krajevsky, Ritzmann and Malhorta (2012) believe that a combined cost-oriented and profitable business will be in business longer than it was internally invested. This suggests that businesses should try to control costs without compromising the quality of their products in an effort to reduce costs. It achieves this goal by adopting various forms of control without reducing maintenance costs. According to Chanbola and Compromise (2013) these cost control systems and / or methods are designed to ensure that operating costs in an organization do not exceed a certain distance. Ensuring efficient use of resources to achieve increased productivity and profitability goals.

The availability of products to consumers is critical to the survival of any manufacturing company, because even the best product with quality, price, and profit must be immediately available to the consumer at the time of demand and should be exchanged before the product becomes competitive. Distribution of these products comes at a cost because the costs are borne by the manufacturer or consumer (Edokpia \& Ohikhure, 2012). It is important to accept very low distribution costs, as this will bring financial benefits to the company.

As travel costs vary with the transport policy imposed by the company, manufacturers and service companies need to make continuous efforts to reduce the cost of travel and transportation models is one tool used for the actualization of this policy (Edokpia \& Amiolenhen, 2016). 
This study looks at how the transportation model can be used to effectively manage costs to maximize profits.

\subsection{Literature Review}

\section{Overview of Transportation Model}

Transport Models are a systematic demonstration of real-world travel. They are tools used to assess the current and future capacity of transport infrastructure options. These types are important in building an effective urban planning practice (Oni, 2009).

Transportation models also known as transportation crisis/problem was first introduced by the French mathematician Monge in 1781, but during World War II Soviet / Russian mathematician and economist Leonid Kontorovich made great strides in this area. As a result, the current problem is sometimes referred to as Monge-Kantorovich's travel problem. Kantorovich and Gaurin (1949) co-authored a paper on transportation problem. Many other fields of science, such as Operation Research, Economics, Engineering, Geographic Information Science and Geography, have contributed to the development of transportation problem. In the field of mathematical systems and engineering books, this is called localization and distribution problem. The origin of transportation model was first introduced by Hitchcock (1941) in a study entitled "The Distribution of a Product from Several sources to numerous Localities". Prior to the introduction of an independent study by Coupmans (1947), this problem was considered an important first step in solving travel problems, known as the "efficient use of the transport system". These are two major contributions to the construction of transport models. The transportation problem got its name because its operating systems determine how to ship goods. In 1951 George B. Dantzig introduced the concept of Linear Programming in solving Transportation models.

The modes of transport are important in addressing many transport systems because they provide: an analytical framework for measuring the current needs of the transport system and assessing future needs to formally assess the impact of transport and land use options.

Modes of transport use statistical relationships to reflect current travel decisions and predict future travel decisions. Mainly, the transport models are Demand Model (Trip Generation, Trip Distribution), Highway Assignment Model (Road Based Public Transport, Private Vehicles, Transport and Other Commercial Vehicles) and Rail, Bus and Ferry Assignment Model (Public Transport and Freight) (Deshmukh, 2012; Mishra, 2017).

Modes of transportation are important because they predict future travel and the number of trips to be made. These estimates are used for investment analysis, environmental impact statements and investment priorities. Models rely less on the travel route and it is important that you have a clear understanding of the proper planning modeling process (Mishra, 2017; Vignax \& Michalevic, 1991) to help create low-cost travel services at low cost and impact on the environment. Lack of planning can lead to heavy traffic congestion, dangerous travel policies, delays in travel plans, adverse environmental impacts and waste of money and resources. As part of the transport planning process, construction take a long time (Ramzan \& Ramzan, 2012; Sen, Som, \& Sinha, 2010).

This model can be used to make strategic decisions in selecting appropriate transport routes such as allocating crop production in bulk depots or distribution areas; such decisions are: making decisions about a place, which means finding a new place, a place of production or an 
office. Transport models can be used to reduce total shipping costs, distribution and shipping costs, and production costs.

\section{Cost control}

One of the benefits of cost control is the ability to keep cash flowing at the required level, that is, by cost control, not being tied to large amounts in the inventory, which restricts stock supply or more in the flow of funds, expansion or adjustment and making money available for other purposes, including maintenance of equipment.

Biggs (2005) believes that effective management of operations in any organization is the responsibility of an effective management team. The following benefits of doing so are significant (Bigs \& Rensing, 2014; Jacobs et al., 2014; Locker, 2000; Cyanbola \& Compromise, 2013).

Cost control provides relevant and systematic information to manage the operations of an organization operating in a competitive environment, providing a clear view of the cost centre within the complex organization so that managers know where to focus; which guarantees an accurate financial report at the end of the year, which allows for efficient and continuous performance, and which promotes and ensures sound evaluation of institutional financial performance.

Hamilton and Martha (2007) argued that managers rely on that financial information and analytics to make alternatives to cost management, or that managers direct the investor to prepare directly to evaluate those options. All costs may not be achievable targets for costcutting measures. For example, in the event of a mass retrenchment, a company could lose a significant portion of its population by releasing skilled workers in their fields, not to mention the degradation of those left behind after mass depletion. Therefore, managers must determine what is strategically important and what is not. Shrank et al (2001) argue that the reduction in variable costs is directly related to product output, such as building materials and costs, which are the basis for significant growing profitability. However, managers should also consider that saving money on a product will undermine the quality or other interest of a strategy such as market time. If a cheap item or a transportation system adversely affects other strategic variables, a small cost savings may not benefit the company in the big picture, which could mean losing sales.

Kashin et al. (1994) describes cost control an ongoing process that starts with the proposed annual budget. It also refers to a management effort that affects the actions, costs, and actions of people in charge. Cost control involves the procedures used to determine whether the actual performance is consistent with the budget.

According to Lucy (2000), in order to maintain a cost-effective system, basic drawings must be followed to obtain the desired results. Performance targets and intentionally acquired costs should be allocated to each work area as long as it is done.

\subsection{Methodology}

Quasi-experimental design using cross sectional survey was adopted. Ten (10) manufacturing companies in Nigeria form the population of this macro level study; participants were drawn from the regional or local offices of these companies in Rivers State, Nigeria. A simple random sampling procedure was used in selecting sample for this study. Participants came from senior, middle and junior managers who understood the concept of transport model and 
cost control. These cadres of staff in these regional offices range between ten and fifteen. The total number of management personnel in this high-level study was 140 . There were 103 staff members from the 10 institutions involved in the study. Of the one hundred and three (103) participants interviewed, ninety-six (96) questionnaires representing 93.20\% were withdrawn, while seven (7) representing 6.80\% were not withdrawn due to time and skepticism of respondents. The Spearman rank order correlation was used to analyze the data collected in this study.

Although participants were recruited from manufacturing companies in Rivers State, Nigeria, the results of this study also apply to other manufacturing companies.

(H01): The use of the transport model does not actually affect the cost of transportation in manufacturing companies

\section{Correlations}

\begin{tabular}{|c|c|c|c|}
\hline & & Northwest_model & $\begin{array}{l}\text { Unit } \\
\text { Cost_shipme } \\
\text { nt }\end{array}$ \\
\hline Spearman's rho & $\begin{array}{rr}\text { Transport } & \text { Correlation Coefficient } \\
\text { Model } & \text { Sig. (2-tailed) } \\
& \mathrm{N}\end{array}$ & 1.000 & $1.000^{* *}$ \\
\hline Coefficient & $\begin{array}{r}\text { Unit Cost_shipmen } \quad \text { Correlation } \\
\qquad \text { Sig. (2-tailed) } \\
\text { N }\end{array}$ & $\begin{array}{r}1.000 * * \\
5\end{array}$ & 1.000 \\
\hline
\end{tabular}

**Correlation is significant at the 0.01 level (2-tailed).

In connection with hypothesis 1, correlation analysis was conducted with transportation model as the independent variable and unit cost of shipment as the dependent variable. Results show that $t_{\text {cal }}=0.000$ and $t_{\text {tab }}$ at $5 \%=0.01$. Since $t_{c a l}<t_{\text {tab }}$, we reject the null hypothesis, that transportation model is not statistically significant to unit cost of shipment at $1 \%$ level of significance. From the table above, the p-value of 0.000 is less than the critical value at $5 \%=0.05$ level of significance; hence the study rejects the null hypothesis that there is no significant relationship between transportation model and unit cost of shipment in Nigerian manufacturing firms. The correlation coefficient of $100 \%$ shows a strong positive relationship between the variables. 
(H02): The application of the shipping pattern does not actually affect the size of the goods shipped.

Correlations

\begin{tabular}{|c|c|c|c|c|}
\hline & & & Northwest_model & $\begin{array}{l}\text { Quantity_Shi } \\
\text { pped }\end{array}$ \\
\hline \multirow{3}{*}{$\begin{array}{l}\text { Spearman's rho } \\
\text { Coefficient }\end{array}$} & Transport & Correlation & 1.000 & $\begin{array}{r}.400 \\
.505\end{array}$ \\
\hline & \multirow[t]{2}{*}{ Model } & \multirow{2}{*}{$\begin{array}{l}\text { Sig. (2-tailed) } \\
\mathrm{N}\end{array}$} & 5 & 5 \\
\hline & & & .400 & 1.000 \\
\hline \multirow[t]{2}{*}{ Coefficient } & Quantity_Shipped & & $\begin{array}{r}.505 \\
5\end{array}$ & 5 \\
\hline & & $\begin{array}{c}\text { Sig. (2-tailed) } \\
\mathrm{N}\end{array}$ & & \\
\hline
\end{tabular}

*Correlation is significant at the 0.05 level (2-tailed).

With respect to Hypothesis 2, the correlation analysis with the transport model is transported as an independent variable and the quantity of goods as a dependent variable. The results show that tcal $=0.505$ and ttab $5 \%=0.05$. From Tcal $>$ ttab, we reject the null hypothesis that the transport pattern is statistically important for the size of the goods shipped at the 5\% importance level. From the table above, the p-value of 0.505 is less than the critical value at the $5 \%=0.05$ significance level; The study therefore rejects the null hypothesis that the application of the transport model does not actually affect the size of the goods transported. The $40 \%$ correlation coefficient shows a weak positive correlation between variables.

(H03): The application of the transport model does not help to ensure the reliability of the delivery of the transport model.

\section{Correlations}

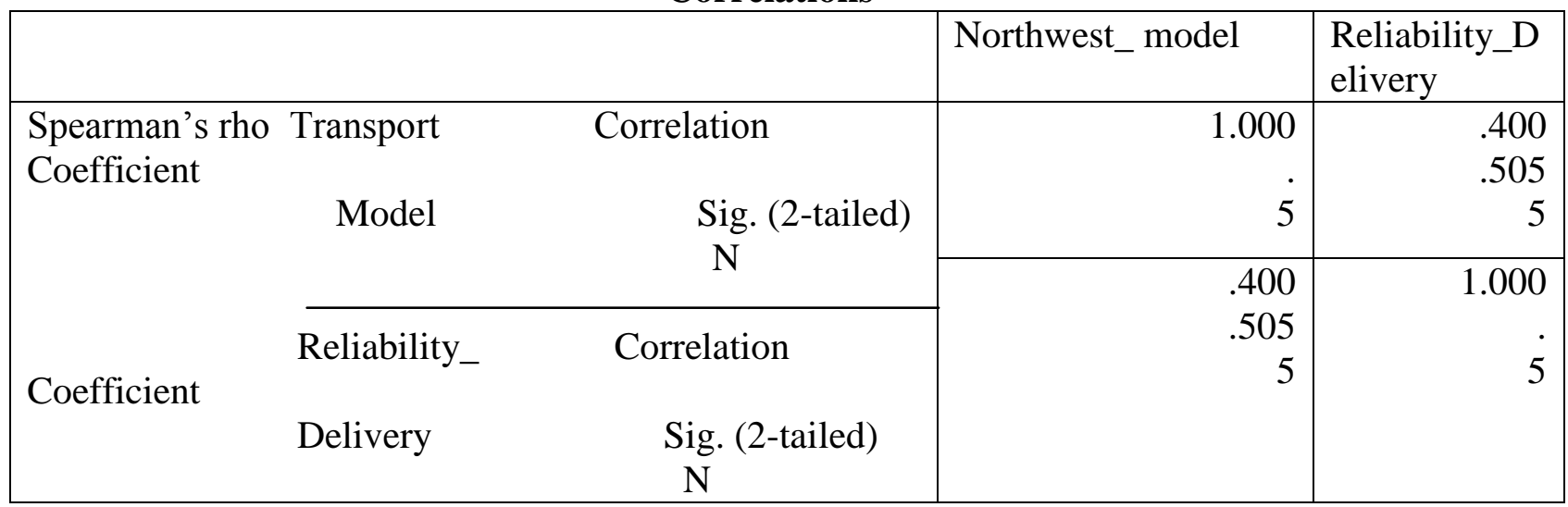

*Correlation is significant at the 0.05 level (2-tailed).

With respect to Hypothesis 3, correlational analysis was performed with the transport model as an independent variable and the reliability of delivery as a dependent variable. The results show that tcal $=0.505$ and ttab $5 \%=0.05$. From Tcal $>$ ttab, we reject the null hypothesis that the transport pattern is statistically important for the reliability of delivery at the 5\% importance level. From the table above, the p-value of 0.505 is less than the critical value at the $5 \%=0.05$ significance level; The study therefore rejects the null hypothesis that the 
application of the transport model does not help to ensure the reliability of delivery in manufacturing companies. The $40 \%$ correlation coefficient shows a weak positive correlation between variables.

\subsection{Discussion of results}

Researchers have described transportation model as an important tool for successfully solving travel problems in organizations and the costs associated with travel by a global manufacturing company. They found that it was not possible for a company to make a temporary or profitable profit without controlling its share of costs, so there is need to use transport models to control the costs of manufacturing companies (Salmaninezad \& Daneshwar, 2012; Tsen \& Hu, 2010). Karel (2007) found that when costs are effectively managed and / or controlled, the profitability of the organization improves and companies become financially strong. As a result of improved performance, customer loyalty is strengthened and social relationships improve. The transport model was committed to boosting product growth in firms, market shares, competitive position, operational efficiency and financial efficiency. In this regard, this study attempts to examine the relationship between the transport model and cost control.

Hypothesis one seeks to test whether the use of transport model affects the cost of transportation in manufacturing companies. This hypothesis was tested using Spearman rank order correlation. Analysis of the data collected revealed that there is a positive relationship between transport model and the unit cost of transporting products from one source to another in the manufacturing companies. The ability for firm to effectively control unit cost of production is to some extent dependent on its wise use of transportation model to help reduce the cost of transporting goods from source to destination.

The second hypothesis examines whether the use of the transport model really affects the size of goods transported. This hypothesis was tested using Spearman rank order correlation. Analysis of the data collected revealed a positive relationship between the use of transport model and the number of goods shipped. When manufacturing companies use transport model, the amount of goods to be transported per time is determined. This keeps companies in good standing and competing in the business space.

The third hypothesis examines whether the use of transport model confirms the reliability of the delivery of products. This hypothesis was tested using Spearman rank order correlation. Analysis of the data collected revealed that there is a positive relationship between the use of transport model and the reliability of delivery of goods from source to destination. The implication of this positive relationship is that when manufacturing companies use or are using transport model, delivery of goods from source to destination is more reliable.

\subsection{Conclusion and Recommendations}

The results of this study revealed a positive relationship between transport model and cost control. This suggests that transport models ensure cost control over Nigerian manufacturing companies. These findings support the argument made by Alam and Rastogi (2011) that transport models are widely used in various fields such as travel, construction, telecommunications, health care and public services because Nigerian manufacturing companies rarely use transport model to solve transport problems. The transport model is used to develop information to assist in decision-making about future development and maintenance of transport systems, but obtaining rational cost control depends on how well 
experienced professionals in the transport sector are knowledgeable in transport models and cost control. Employees in the transport sector/department can accumulate knowledge and skills through job training, but must also receive specialized training in the use of transport models in order to effectively manage costs and maximize profits through these uses.

The effective use of transportation models increases the profitability of manufacturing companies by reducing costs. This study supports Deshmukh's (2012) position on arranging exports from transport model sources to locations, thereby reducing overall travel costs. However, a smart plan is needed to help create high-quality transport resources that have a low impact on the environment and cost. Failure to plan can result in heavy traffic congestion, hazardous travel policies, unwanted land use policies, environmental impact, and financial and resource wastage. Successful use of transportation models not only reduces overall costs but also delivery time. This increases the volume of goods delivered, reduces unused capacity, ensures the reliability of delivery, and security of delivery. The results of the study revealed an important relationship between the effectiveness of transport models and the quantity of goods transported. This model helps you to know how to meet the demand using the appropriate transport route depending on the available storage and distribution facilities. The results of this study are comparable to the results of Yim et al. (2011) that opined that the use of the transport model leads to an increase in delivery time to manufacturing companies. In Nigeria today, the survival of manufacturing companies is largely determined by their ability to effectively manage costs, and the use of transportation models is a sure-fire way to achieve this. As Bigs and Rensing (2014) noted, cost control provides relevant and systematic information to control the activities of an organization operating in a competitive environment; It provides a clear view of the cost centre in a complex organization so that managers know where to focus their attention on effectively implementing a cost management approach. Nigerian manufacturing companies should start focusing on this mode of operation, that is, the use of transport model that can be created to achieve this goal.

Research has shown that the state of Nigeria's roads is adversely affecting the functioning of the roads. When delivery time is verified using a model, the condition of the road is not a matter for the model, and the product distributors cannot verify the condition of the roads. This makes it difficult for the model to accurately measure the delivery time. Usually, goods trucks go down the roads because the roads in Nigeria are not good.

Research continues to confirm that the use of the transport model leads to the acquisition of unused capacity in manufacturing companies. It helps companies reduce waste, thus controlling costs; and the delivery trucks will bring more money to the company.

Finally, this research confirms that the use of the transport model helps to ensure the reliability of delivery of goods from source to destination. However, as mentioned earlier, there are many things that can prevent this from happening. These include bad road network, driver negligence, mechanical failure of the truck, etc.

Based on the results of this study, the following recommendations were made:

As the use of transport models improves the cost of transporting goods from source to location in manufacturing companies, Nigerian manufacturing companies should train their employees on how to use transport models in managing travel costs, especially those in the transport sector. It also ensures increasing the profitability of the company. 
Since transport models have a positive impact on the profitability of manufacturing companies, companies should not only train its employees in the use of transport models, but also decide on the use of transport model in determining quantity of goods to move from one source to another.

Manufacturing companies must use transport models in determining the quantity of goods to be shipped before goods are shipped. This helps to reduce waste and overcrowding on delivery trucks.

Manufacturers should use transport models to determine the maximum delivery time but in doing so, they should take into account the state of Nigeria's roads, the road value of their delivery trucks and the negligence of their drivers. Truck drivers need to be well-trained and / or well-educated and well-informed about the importance of being on time in their delivery schedule.

As the state of Nigeria's roads could affect the use of transport models, the government needs to do more in road repairs and rehabilitation. As part of their social responsibility, manufacturing companies should help repair and / or maintain these damaged roads their heavy trucks use.

Manufacturing companies should use transport model to determine underused capacity and ensure such capacities are put into productive use. When under-utilized capacity is not commensurate with the day-to-day operations of the company's business, they should be discarded and the proceeds transferred to more productive areas.

Companies involved in delivery of goods and services should use more than a delivery pattern to help ensure delivery reliability. Unreliable deliveries must be cancelled and delivery trucks / vans transferred to other trusted routes.

Contrary to the arguments of other researchers of the past, although transport models are useful in solving transportation problems, their application in Nigeria is hampered by poor road conditions in Nigeria, negligence of truck drivers, the number of trucks transporting goods, and so on. Manufacturing companies in Nigeria therefore need to use transportation model in solving transport problems; these teething problems also need to be addressed. Failure to address these issues will leave the application of transportation models to be just an academic exercise without any practical relevance. 


\section{References}

Alam, T., \& Rastogi, R. (2011). Transportation problem: extensions and methods-an overview. VSRD International Journal of Business \& Management Research, 1(2), 121-126.

Anthony, R. N., \& Govindarajan, V. (2007). Management control systems.

Biggs, R., \& Remsing, C. C. (2014). Cost-extended control systems on Lie groups. Mediterranean Journal of Mathematics, 11(1), 193-215.

Carrell, J. (2007). Intellectual capital: an inquiry into its acceptance. Business renaissance quarterly, 2(1), 67.

Cashin, J. A., Polimeni, R. S., \& Handy, S. (1994). Schaum's Outline of Cost Accounting, 3rd, Including 185 Solved Problems: McGraw Hill Professional.

Cooper, R., \& Slagmulder, R. (1999). Activity-based cost management system architecture-part I. Strategic Finance, 81(4), 12.

Deshmukh, N. (2012). An Innovative method for solving transportation problem. International Journal of Physics and Mathematical Sciences, 2(3), 86-91.

Edokpia, \& Amiolemhen, P. (2016). Transportation cost minimization of a manufacturing firm using genetic algorithm approach. Nigerian Journal of Technology, 35(4), 866873.

Edokpia, \& Ohikhuare, K. O. (2012). Transportation cost minimization of a manufacturing firm using linear programming technique. Paper presented at the Advanced materials research.

Ferreira, L. D., \& Merchant, K. A. (1992). Field research in management accounting and control: a review and evaluation. Accounting, Auditing \& Accountability Journal, $5(4), 0-0$.

Hitchcock, F. L. (1941). The distribution of a product from several sources to numerous localities. Journal of mathematics and physics, 20(1-4), 224-230.

Jacobs, F. R., Chase, R. B., \& Lummus, R. R. (2014). Operations and supply chain management: McGraw-Hill/Irwin New York, NY.

Kantorovich, \& Gavurin, M. (1949). Application of mathematical methods to problems of analysis of freight flows. Problems of raising the efficiency of transport performance, $110-138$.

Koopmans, T. C. (1947). Measurement without theory. The Review of Economics and Statistics, 29(3), 161-172.

Krajewski, L. J., Ritzman, L. P., \& Malhorta, M. K. (2012). Operations Management: Processes and Supply Chains: Pearson education.

Lockyer, K. (2000). Factory and production. In: London, DP Publishers.

Lucey, T. (2002). Costing: Cengage Learning EMEA.

Mishra, S. (2017). Solving Transportation Problem by Various Methods and Their Comparison. International Journal of Mathematics Trends and Technology (IJMTT)Volume, 44.

Monge, G. (1781). Mémoire sur la théorie des déblais et des remblais. Histoire de l'Académie Royale des Sciences de Paris.

Oni, S. (2009). Public-Private Partnership relationships in urban transportations in Nigeria.

Ramadan, S. Z., \& Ramadan, I. Z. (2012). Hybrid two-stage algorithm for solving transportation problem. Modern Applied Science, 6(4), 12-22.

Salmaninezhad, R., \& Daneshvar, M. (2012). Relationship analysis between intellectual capital and knowledge management (Case study: Tehran Science \& Technology 
Park). Interdisciplinary Journal of Contemporary Research in Business, 3(10), 135143.

Sen, N., Som, T., \& Sinha, B. (2010). A study of transportation problem for an essential item of southern part of north eastern region of India as an OR model and use of object oriented programming. International Journal of Computer Science and Network Security, 10(4), 78-86.

Siyanbola, T. T., \& Raji, G. M. (2013). The Impact of Cost Control on Manufacturing Industries' Profitability. International Journal of Management and Social Sciences Research, 2(4), 1-7.

Tsen, S.-h., \& Hu, H.-l. (2010). A study of the organizational competitiveness and intellectual capital indicators of international tourist hotels. Human Resource Management Student Newspaper, 10(1), 79-104.

Vignaux, G. A., \& Michalewicz, Z. (1991). A genetic algorithm for the linear transportation problem. IEEE transactions on systems, man, and cybernetics, 21(2), 445-452.

Wyszewianski, L. (1986). Financially catastrophic and high-cost cases: definitions, distinctions, and their implications for policy formulation. Inquiry, 382-394.

Yim, K. K., Wong, S., Chen, A., Wong, C. K., \& Lam, W. H. (2011). A reliability-based land use and transportation optimization model. Transportation Research Part C: Emerging Technologies, 19(2), 351-362. 